\title{
Palliative Care Situation in French Speaking African Countries: Example of the Sakoira Integrated Health Center in Republic of Niger (West Africa)
}

\author{
Soumaila Boubacar ${ }^{1,2,3,{ }^{*} \text {, Djibrilla Ben Adji }}{ }^{3,5}$, Youssoufa Maiga ${ }^{4}$, Malam Abdou Badé ${ }^{6,8}$, \\ Alassane Mamadou Diop ${ }^{2}$, Youssouf Yayé $e^{3}$, Moustapha Ndiaye ${ }^{2,7}$, Eric Adehossi ${ }^{5,8}$ \\ ${ }^{1}$ Integrated Health Center of Sakoira, District Hospital, Tillabéri, Niger \\ ${ }^{2}$ Department of Neurology, Fann National Teaching Hospital, Dakar, Senegal \\ ${ }^{3}$ Ministry of Public Health, Niamey, Niger \\ ${ }^{4}$ Department of Neurology, Gabriel Touré University Hospital, Bamako, Mali \\ ${ }^{5}$ Department of Medicine, National Hospital, Niamey, Niger \\ ${ }^{6}$ Department of Hematology, National Hospital, Niamey, Niger \\ ${ }^{7}$ Faculty of Medicine, Cheikh Anta Diop University, Dakar, Senegal \\ ${ }^{8}$ Faculty of Health Science, Abdou Moumouni University, Niamey, Niger
}

Email address:

abounadjma@yahoo.fr (S. Boubacar)

${ }^{*}$ Corresponding author

\section{To cite this article:}

Soumaila Boubacar, Djibrilla Ben Adji, Youssoufa Maiga, Malam Abdou Badé, Alassane Mamadou Diop, Youssouf Yayé, Moustapha Ndiaye, Eric Adehossi. Palliative Care Situation in French Speaking African Countries: Example of the Sakoira Integrated Health Center in Republic of Niger (West Africa). Central African Journal of Public Health. Vol. 3, No. 1, 2017, pp. 8-10. doi: 10.11648/j.cajph.20170301.12

Received: August 17, 2016; Accepted: November 27, 2016; Published: January 9, 2017

\begin{abstract}
In Niger, palliative care is a necessity in everyday medical practice. However, the setting up of structures and / or mobile teams specifically dedicated to palliative medicine still faces enormous challenges. Most patients who consult for noncommunicable disease or specifically for tumors or other incurable illnesses as some neurological diseases come advanced stages, requiring palliative care whereas there is as yet no national structure specifically dedicated to palliative care. No domain of research in palliative care is developed in Niger. No specific scientific work on palliative care have been conducted and published in Niger. This testifies to the lack of promotion of this specialty in Niger. So the ignorance of palliative care, access to morphine and ordinary molecules fight against pain are a real obstacle to the practice of palliative medicine in Sakoira Integrated Health Center (Tillabéri) in republic of Niger.
\end{abstract}

Keywords: Palliative Care, Niger, Morphine, French, Africa

\section{Introduction}

In sub-Saharan Africa, Niger is developing country with a population about 17.807.117 million on an area of 1276000 $\mathrm{km}^{2}$ [1] two-thirds are located in area Saharan [2]. It is located between parallels $11^{\circ} 37$ and $23^{\circ} 33$ of North latitude one hand, and meridians $16^{\circ}$ East and $10^{\circ} 0$ of the other West longitude. It's a steppe country, limited to the West by Burkina Faso, to the east by Chad, north by Algeria and Libya, on the south by Benin and Nigeria, and to the northwest by Mali. The geographical situation of Niger made the country a hub for trade between Africa North and Africa south of the Sahara. [2]. Sakoira is a rural community of Tillabéri department. It is located $122 \mathrm{~km}$ from Niamey (capital of Niger). Its population was estimated at 27,076 inhabitants, 13,001 men 14,075 women. It is a common composed of 6 villages and 5 tribes. Its area is $173 \mathrm{~km}^{2}$ with 1 following geographical coordinates $14^{\circ} 16^{\prime} 60^{\prime}$ 'north and $1^{\circ} 24^{\prime} 0^{\circ}$ 'East (Monograph of the municipality of Sakoira).

The national policy of the Niger health based on Primary 
Health Care at through the development of health districts. This is taken to adapt the consequences of financial crises and to take into account the commitments International which Niger has subscribed, including those related to the achievement the Millennium Development Goals (MDGs) and those of the Plan of Economic and Social Development (PDES 2012-2015). [2] However in Niger, palliative care is again a necessity in everyday medical practice. However, the setting up of structures and / or mobile teams specifically dedicated to palliative medicine still faces enormous challenges that we raised here.

So this work is an update on the status of research, teaching and services relating of palliative medicine in Sakoira Integrated Health Center (Figure 1) in Niger and literature review.

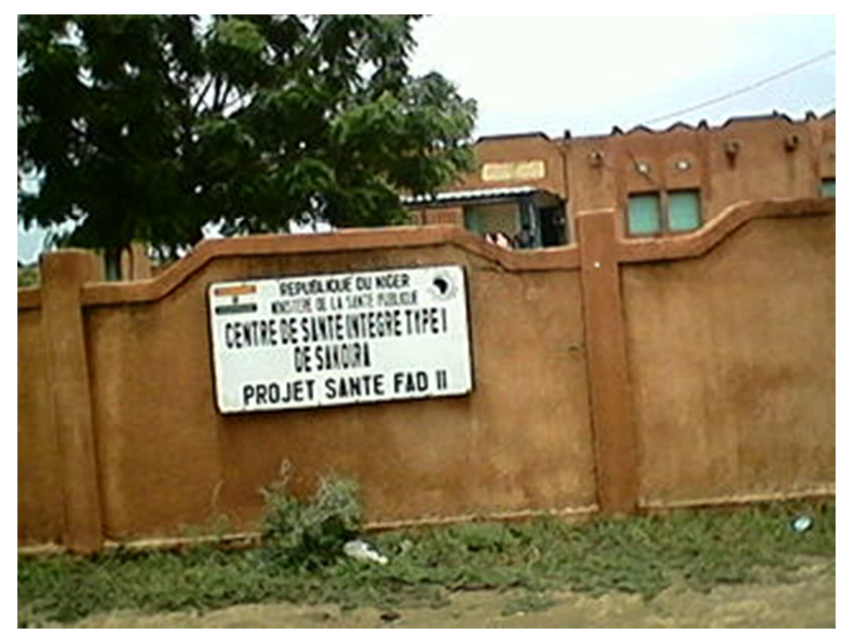

Figure 1. Sakoira Integrated Health Center, in Tilabéri (Republic of Niger).

\section{Palliative Care Situation}

In republic of Niger (West Africa), most patients who consult for non-communicable disease or specifically for tumors or other incurable illnesses as some neurological diseases come advanced stages, requiring palliative care whereas there is as yet no national structure specifically dedicated to palliative care. In contrast, about some ten health workers, doctors and paramedical staff have received intensive training in palliative care by specialists. In 2013, four physicians have been trained in palliative care at Hospice Africa Uganda, through theoretical and practical training in teaching hospitals in Kampala and other regional hospices Uganga.). Then these Nigeriens agents have in turn trained under tutelage of Ministry of Health forty other healthcare professionals from all parts of the country. In sakoira health center (Tillaberi) hundreds of patients with chronic illnesses benefited from palliative care but only 3 of them had received morphine. Other training sessions were held periodically at the National Hospital of Niamey (Niger's capital). No domain of research in palliative care is developed in Niger. Ignorance of palliative care, access to morphine and ordinary molecules fight against pain are a real obstacle to the practice of palliative medicine in our country.
This testifies to the lack of promotion of this specialty in Niger. So palliative medicine is very little known and practiced in Niger from where the need for change in public healthcare policy on palliative care.

\section{Discussion}

Palliative care involves the physical, emotional, practical, and spiritual aspects of the patient's suffering in the course of the illness [3]. Palliative care, end of life care, care of the "dying," are a specialty. Yet their practice crosses all disciplines of cardiology to oncology, neurology to geriatrics. They relate to all ages, from pediatrics to geriatrics services [4]. According to the regional office for the WHO African (Afro), non communicable diseases (atherosclerosis, diabetes, cancer and other chronic diseases) should represent half of 2030 deaths against a quarter in 2004. Sixty-four percent of new cancer cases worldwide are registered in developing countries [5]. An estimated 421000 people died of cancer in sub-Saharan Africa in 2008. However, poor access to health services and few cancer registries on the continent make this a probable underestimate. Because availability of health services is low and access is poor, about $80 \%$ of cancers on the continent are incurable at the time of detection and diagnosis [6, 7]. Until 2009, 7031 cases of cancer were recorded in Niger [8]. According to WHO, it is becoming a public health problem in developing countries by increasing its frequency [9].

More Hematologic malignancies are serious diseases that affect many people worldwide. They mark the entry into a heavy and long-care process. The African continent is not spared. The fight against this scourge in Africa is underpinned many challenges, despite the lack or inadequacy of material and financial resources, and lack of qualified staff [10]. Including palliative care is a real need in African countries in general and Niger in particular. Also the health policy particularly to the search for equity, improving quality of care and accessibility to a larger number of vulnerable people (women, children, disabled people, people in rural areas...) to health services. However, the implementation of this policy has not been effective and consequently has not had the expected impact on key health indicators, namely the strong maternal and child mortality and the high mortality associated with prone diseases epidemic. This is mainly due to: inadequacies in the choice of strategies, the low attention given to financial protection for users and health inequalities between rural and urban areas the system's weakness monitoring and evaluation and governance.

The majority of these chronic diseases share common incurable pain. The pain affects approximately $60 \%$ of patients with cancer. It is not sufficiently taken into account, especially in developing countries. It greatly affects the quality of life of patients and requires adequate care can include, where necessary, morphine [11]. However, morphine is expensive for patients victims of incurable diseases. While in Niger, as in other West African countries, the low level of 
income does not allow the majority of patients to obtain morphine.

Yet Africa french speaking countries was, the host of the department Material World Forum on Research for health at Bamako in November 2008, the international momentum is conducive to debates on free health care [12]. The contemporary debate in the field of financing of health is the suppression of direct payment [12].

The free care is not yet in many African countries. In most African countries, programs of prevention and fight against cancer are lacking or have shortcomings. Certainly caregivers will face many problems, but their determination must be stronger to cope. It takes a lot communication to help those in great suffering patients [10]. This determination requires practitioners awareness. This is possible only through a training of all caregivers in palliative care. We must therefore provide care training Palliative health staff in hospitals and the community, teachers and community leaders; they can in turn pass on their knowledge to community health workers, volunteers and families [10].

In 2013, four physicians have been trained in palliative care at Hospice Africa Uganda, through theoretical and practical training in teaching hospitals in Kampala and other regional hospices Uganda [13]. Forty health workers were trained in palliative care at national level. To facilitate communication between patient and health workers use a booklet that lists questions that can be asked the doctor by the patient during a consultation supportive care and palliative care showed his interest in facilitating communication $[14,15]$. This linguistic difficulty of access to English also a big handicap caregivers African French speaking countries because most people do not have access to documents written in English. while palliative care is not developes in these African french speaking countries compared to English-speaking African countries such as Uganda for example.

A booklet listing of issues correlation with different areas of concern Patient has been designed and approved by the Medical Psychology Research Unit (MPRU) University Sydney, Australia [16]. This booklet was adapted in French to respond to these communication needs between patients and health workers [17].

\section{Conclusion}

For Palliative Care in Niger and Africa in general, our public health politicals electorals must consider the need investissmement in the field of palliative medicine to help people in later life or chronically ill. The grant of morphine is one of the major challenges faced in this problem. Palliative medicine is very little practiced in Niger. There is the need for a reorientation of public health policy on palliative care for a better grip holistic chronic disease increasingly emerging in Africa in general and in Niger in particular.

\section{References}

[1] Le Niger en 2014. http://www.stat-niger.org/. Institut National de la Statique.

[2] www.snis.cermes.net/download/Annuaire_statistiques_2014

[3] Harding R, Powell RA, Downing J, Connor SR, MwangiPowell F, Defilippi K, et al. Generating an African palliative care evidence base: the context, need, challenges, and strategies. J Pain Symptom Manage 2008; 36: 304-9.

[4] M. PERRIER, J.-C. FONDRAS. SOINS PALLIATIFS. 2004. P216.

[5] IARC, (International agency for research on Cancer). World cancer report 2008. Lyon: IARC, 2008.

[6] Kanavos P. The rising burden of cancer in the developing world. Ann Oncol 2006; 17 (suppl 8): viii 15-23.

[7] Anim JT. Breast cancer in sub-Saharan African women. Afr J Med Med Sci 1993; 22: 5-10.

[8] Garba SM, Zaki HM, Arfaoui A, Hami H, Soulaymani A, Nouhou H, Quyou A. Épidémiologie des cancers au Niger, 1992 à 2009. Bull Cancer 2013; 100: 127-33.

[9] Organisation mondiale de la santé. Action mondiale contre le cancer. Le Centre international de recherche sur le cancer (CIRC), 2005 (version révisée).

[10] Tazi I, Nafil H, Mahmal L. Les soins palliatifs en hématologie: quel avenir en Afrique? The Pan African Medical Journal. 2011; 8: 8.

[11] J Didi-Kouko Coulibaly, I Adoubi, M Touré, A Oseni, KA Echimane. (2009). Les difficultés de la prise en charge par la morphine de la douleur en cancérologie: expérience ivoirienne. 2009: 703-7.

[12] Valéry Ridde, Karl Blanchet. Débats et défis autour de la gratuité des soins en Afrique: «retour vers le futur»? Cahiers Santé vol. 19, $\mathrm{n}^{\circ} \quad 2, \quad$ avril-mai-juin 2009. 10.1684/san.2009.0161.

[13] www.hospiceafrica.or.ug/index.php/la-formation-pour-1initiation-des-soins-palliatifs-en-afrique

[14] Dimoska A, Tattersall MH, Butow PN, Shepherd H, Kinnersley P. Can a "prompt list" empower cancer patients to ask relevant questions? Cancer 2008; 113: 225-37.

[15] Clayton J, Butow P, Tattersall M, et al. Asking questions can help: development and preliminary evaluation of a question prompt list for palliative care patients. Br J Cancer 2003; 89: 2069-77.

[16] Clayton JM, Butow PN, Tattersall MH, Devine RJ, Simpson JM, Aggarwal G, et al. Randomized controlled trial of a prompt list to help advanced cancer patients and their caregivers to ask questions about prognosis and end-of-life care. J Clin Oncol. 2007; 25: 715-723.

[17] Fouquet C, Brédart A, Bouleuc C. Adaptation en langue française d'un livret de questions à destination des patients atteints de cancer et de leurs proches, dans le cadre d'une consultation en soins de support et soins palliatifs en oncologie. Bull Cancer 2012; 99: 693-701. 